\title{
Características hidráulicas das camadas aqüíferas da Formação Guabirotuba e o potencial explotável na região da Bacia do Iraí, Curitiba - Paraná
}

\author{
Hydraulic characteristics of the aquifer beds of the Guabirotuba Formation and its exploitable \\ potential in the Iraí Basin region, Curitiba - Paraná \\ ERNANI FRANCISCO DA ROSA FILHO *, EDUARDO CHEMAS HINDI *, LUIZ EDUARDO MANTOVANI * GUSTAVO \\ BARBOSA ATHAYDE** \\ * UFPR/DEGEOL/LPH - Laboratório de Pesquisas Hidrogeológicas \\ ** Doutorando em Geologia na UFPR
}

\begin{abstract}
Resumo
O objetivo do trabalho é determinar as características hidráulicas das camadas aqüíferas da Formação Guabirotuba e o potencial explotável na região da Bacia Hidrográfica do Irai, mais especificamente de uma área da sub bacia do Canguiri. Para alcançar estes objetivos é estabelecido a potenciometria das águas armazenadas na Formação Guabirotuba e através delas estabelecidas as direções principais de fluxos, caracterizando as áreas de descarga do aqüífero. A área de estudo está situada $15 \mathrm{~km}$ de quilômetros de Curitiba, na sua porção nordeste, ao entorno da barragem do Irai. Esta formação é predominantemente constituída por pelitos, sendo que na sua base, especificamente na área de estudo, ocorrem camadas de areias e de cascalhos com espessuras que variam entre 10 e $15 \mathrm{~m}$. Num único poço perfurado nesses sedimentos foi extraída uma vazão de $80 \mathrm{~m} 3 \times \mathrm{h}-1$, tendo ocorrido a precipitação de ferro e manganês nas aberturas das secções filtrantes; o aproveitamento dessas águas exige tratamentos contínuos para a eliminação dos elementos mencionados. O resultado da simulação matemática mostra que as águas do lago do Irai recarregam o aqüífero, sendo seu escoamento em direção contrária ao escoamento das águas freáticas e das águas da rede de drenagem da região. A porosidade efetiva dos sedimentos que constituem os arenitos arcoseanos é em média $28 \%$ e o coeficiente de armazenamento é cerca 5 × 10-4, a permeabilidade gira entre 1,22 × 10-4 e 1,96 × 10-4 m x s-1, a transmissividade varia de 3,6 a 7,6 $\mathrm{m} 2 \times \mathrm{h}-1$, a velocidade média de fluxo varia de 6 × 10-3 a 3 × 10-6 m x s-1 e a vazão explotável através de uma bateria de 15 poços tubulares corresponde a $150 \mathrm{Lx} \mathrm{s}-1$.
\end{abstract}

Palavras-chave: aqüífero Guabirotuba; Iraí; água subterrânea

\begin{abstract}
The main objective of this work is to determine the hydraulic characteristics of the aquifers layers of Lower Pliocene sedimentary sequences in Guabirotuba Formation and by this way evaluate the exploitable groundwater potential in the Upper Iguaçu Irai river basin. To achieve these goals the potentiometry of water stored in Guabirotuba formation was established to set the main directions of groundwater flows, characterizing the discharge areas of the aquifer. The study area is located 15km NNE from Curitiba urban area, at the vicinity of the Irai river dam. The Guabirotuba Formation consists predominantly of clays (aluminous smectites and interstratified), and at its lower level, specifically in the study area, there are unconsolidated sands and gravels layers with a thickness ranging between 10 to $15 \mathrm{~m}$. In a single tube well drilled in these sediments the discharge range was of $80 \mathrm{~m} 3 \times \mathrm{h}-1$, its waters show precipitation of iron and manganese in the filter sections. So that the use of such water requires continuous treatment to eliminate these elements. The mathematics simulations show the contributions of Lake Irai waters to the recharge of Guabirotuba aquifers. Their flow is in the opposite direction of the groundwater flow, and also opposite to the general discharge direction of the water drainage network in this region. The granules effective porosity in arcosic sandstone is $28 \%$ in average, and the storage coefficient is about $5 \times 10-4$, permeability varies between $1.22 \times 10-4$ and $1.96 \times 10-4 \mathrm{~m} \times \mathrm{s}-1$,the transmissivity varies from 3.6 to 7.6 $\mathrm{m} 2 \times \mathrm{h}-1$, the mean flow velocity ranges from $6 \times 10-3$ to $3 \times 10-6 \mathrm{~m} \times \mathrm{s}$-1and the total exploitable discharge for a battery of 15 tube wells corresponds to $150 \mathrm{~L} \times \mathrm{s}-1$.
\end{abstract}

Keywords: Guabirotuba aquifer; Iraí, Groundwater 


\section{Introdução}

Em épocas que cada gota de água se torna imprescindível, todas as possibilidades de captação de mananciais superficiais e subterrâneos são importantes. Já houve períodos de estiagens na Região Metropolitana de Curitiba (RMC) que tornou necessária até a captação das águas armazenadas em algumas cavas existentes na calha do rio Iguaçu, sem a qual não haveria a possibilidade de fornecimento de água para uma parcela da população de Curitiba. Em tendo sido possível captar este tipo de manancial, tratando-o adequadamente para o consumo humano, as águas armazenadas nas camadas aqüíferas da Formação Guabirotuba também não devem ser descartadas, mesmo com a comumente ocorrência de seus elevados teores de ferro e de manganês. Em se tratando de águas que se encontram armazenadas nos interstícios de seus grânulos, é importante o conhecimento de suas fontes de recarga, que neste caso específico, também indicam ser provenientes do lago da barragem do Irai.

\section{Objetivos}

O presente trabalho tem como principal objetivo a caracterização dos parâmetros hidráulicos das camadas aqüíferas da Formação Guabirotuba e por meio deles determinar o potencial explotável através de simulação matemática, na sub bacia do Canguiri, afluente da margem direita do rio Irai.

\section{Região de estudo}

\subsection{Localização}

A região sobre a qual foram desenvolvidos os estudos, está localizada aproximadamente $15 \mathrm{~km}$ a nordeste da cidade de Curitiba, nas proximidades do Parque de Exposição Castelo Branco, no município de Pinhais-PR, Brasil. O Mapa de localização da área, incluindo a delimitação da barragem do Irai e a área investigada, é mostrado na figura 1 .

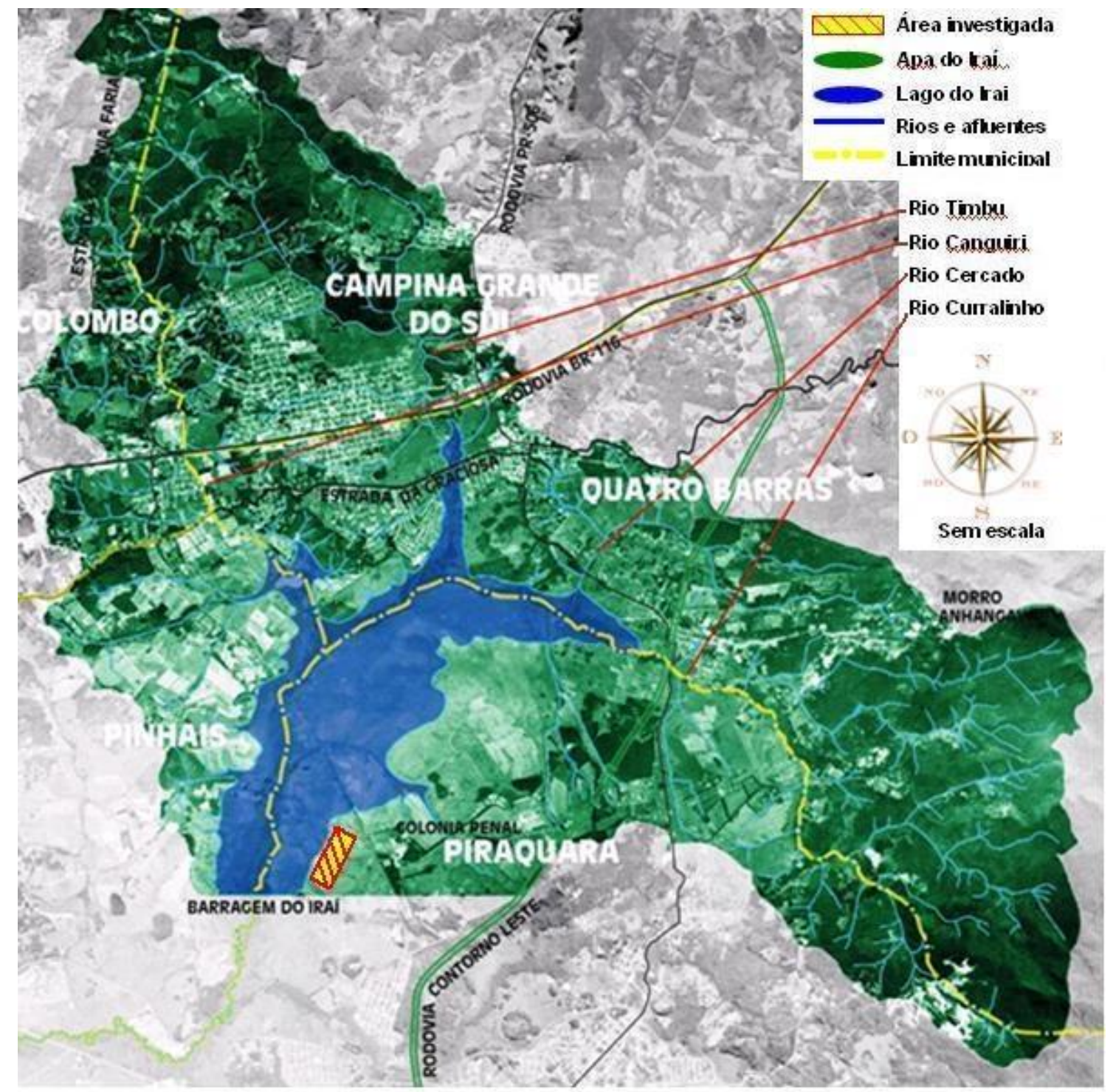

Figura 1 - Mapa de localização da área de estudo. 


\subsection{Geologia}

A área de abrangência de estudo é representada pelos sedimentos da Formação Guabirotuba. Esta formação encontra-se assentada sobre migmatitos e rochas similares que constituem o Complexo Atuba, também comumente denominadas de Embasamento Cristalino.

As primeiras considerações sobre a litologia, espessura, idade, rocha-fonte e origem dos sedimentos da Bacia de Curitiba foram referenciadas por OLIVEIRA e LEONARDOS (1943). De acordo com CARVALHO (1936), nas bordas da bacia predominam cascalhos grosseiros e na sua parte central, sedimentos argilosos com intercalações de areia grossa; os autores op. cit., interpretam essas ocorrências como conseqüência de uma deposição em ambiente fluvial meandrante com sucessivos ciclos recorrentes de regime de baixa e elevada energia. Dentre outros trabalhos, igualmente relevantes sobre o assunto, destacam-se OLIVEIRA e LEONARDOS (1943), MAACK (1947), ALMEIDA (1952), COUTINHO (1955), BIGARELLA \& SALAMUNI (1952a; 1959; 1962), BIGARELLA J.J.; AB SABER \& BIGARELLA (1961), BIGARELLA (1971), LOPES (1966), MURATORI (1966), MARINI (1967), FUCK (1966; 1967a), TREIN (1969), BERG e LOURENÇO (1973), BECKER (1982), PETRI \& FULFARO (1983), SALAMUNI (1988) e SALAMUNI e STELLFELD (2001).

Os sedimentos da Bacia de Curitiba, excetuando-se os depósitos aluvionares recentes, constituem a Formação Guabirotuba. BECKER (1982), com base em critérios geomorfológicos, propôs a subdivisão desta formação em três unidades distintas, a saber: a) Formação Guabirotuba (sedimentos basais); b) Formação Tinguis (sequência superior); e c) Formação Boqueirão (sedimentos arenáceos, discordantes dos migmatitos). Segundo esta autora, a Formação Boqueirão, especificamente, teria sido depositada durante o Pleistoceno Superior, num ambiente de amplos vales com canais anastomosados prevalescentes sob condições climáticas mais severas, as quais precederam o clima atual, responsável pela deposição dos aluviões modernos.

MURATORI et al (1982), com base em estudos gravimétricos, acrescentam que a paleogeografia da região esteve sob a ação de uma tectônica recente, o que teria influenciado de forma significativa no represamento dos sedimentos. A maior parte dos depósitos aluvionares da região, os quais encontram-se inclusive orientados segundo drenagens condicionadas às direções de fraturamentos do embasamento cristalino, aliados à existência de pequenas falhas geológicas na Formação Guabirotuba, permitem sugerir a ação de neotectonismo na Bacia de Curitiba.

SALAMUNI (1988) aponta, dentre outras considerações, a existência de um controle morfotectônico evidenciado pela posição discordante das porções do embasamento em relação aos sedimentos da Formação Guabirotuba.

Resultados de análises granulométricas de amostras de superfície realizadas por ARCHELA (1986), demonstram predominância da fração argilosa sobre a fração com granulometria superior a $0,062 \mathrm{~mm}$. Com referência ao material arenoso, predomina a fração grossa, na faixa de 57
$\%$, enquanto cerca de $37 \%$ apresenta diâmetro médio correspondente a areia média e apenas $6 \%$ de areia fina. De acordo com a classificação de Shepard é destacado dois grupos granulométricos distintos na Formação Guabirotuba; um de granulação mais grossa, constituído por areias, areias sílticas e areias sílticas-argilosas, e outro de granulação mais fina, constituído por argilas sílticas e silte argiloso. É destacado, neste mesmo estudo, que as porcentagens de feldspatos em relação aos minerais de quartzo, chegam a atingir valores superiores a $50 \%$.

Os sedimentos da Bacia de Curitiba, excetuando-se os depósitos aluvionares recentes, constituem a Formação Guabirotuba, a qual teria sido depositada durante o Pliopleistoceno Superior, num ambiente de amplos vales com canais anastomosados (Bigarella e Salamuni 1958a). Tratase predominantemente de sedimentos pelíticos, situados em sua maior parte na seqüência de topo, ocorrendo localmente lentes de areias arcoseanas, geralmente na sua porção basal. Os sedimentos da Formação Guabirotuba atingem espessuras máximas da ordem de $80 \mathrm{~m}$ na porção central da Bacia de Curitiba. Os sedimentos pelíticos são predominantes, sendo que as camadas arcoseanas, com estratificações incipientes, ocorrem sob a forma tabular e não raramente lenticular.

\subsection{Hidrogeologia da Formação Guabirotuba}

A área com melhores características hidrogeológicas da Formação Guabirotuba está inserida na Bacia Hidrográfica do Irai, mais especificamente na sub bacia do rio Canguiri. Nesta área está mapeada uma estrutura do tipo graben, sobre a qual estão depositados os sedimentos mais grossos da Formação Guabirotuba. Estes sedimentos ocorrem sob a forma de lentes descontínuas e de camadas contínuas constituídas por areias arcoseanas e cascalhos cujas espessuras variam entre 4 e $15 \mathrm{~m}$. Existe, nesta área, uma bateria de poços perfurados pela Companhia de Saneamento do Paraná (SANEPAR), cuja produção de cada poço gira em torno de $20 \mathrm{~L}$ x s-1. É importante destacar que estes poços encontram-se lacrados por conseqüência da precipitação de ferro e manganês junto as aberturas dos filtros.

\subsubsection{POROSIDADE}

A porosidade foi determinada através de um Perfil Sônico, realizado pela HIDROLOG - Serviços de Perfilagens Ltda, corrido no poço no 2 da Estação Experimental de Pesquisas Hidrogeológicas da UFPR, na Fazenda Canguiri (Girão Nery e Rosa Filho, 1994). O referido perfil sônico corresponde apenas ao intervalo composto por areias arcoseanas, entre 34 e $41 \mathrm{~m}$ de profundidade.

De acordo com GIRÃO NERY (1994), a equação que permite a determinação da porosidade através de perfis sônicos pode ser representada da seguinte forma:

$$
P=\frac{(t-t m a)}{(t f-t m a)} \cdot \frac{(100)}{(t s h)}
$$


onde, $\quad P=$ porosidade percentual calculada com sônico; $t=$ tempo do som lido defronte ao aqǘfero (em us/pé); tma $=$ tempo do som nos grãos ou matriz do aqüífero (arenito $=55,5$ us/pé); tf $=$ tempo do som no fluido intersticial do aqüífero (água doce $=200$ us/pé); $t s h=$ tempo do som nos siltitos (valor razoável para a área $=180$ us/pé).

O tempo de trânsito registrado no intervalo entre 34 e $41 \mathrm{~m}$, corresponde a 155-156 microsegundos/pé. A aplicação destes valores na equação 1 , aponta uma porosidade total da ordem de 38-39\%, que de acordo com a hipótese de LEVORSEN (1954), a porosidade efetiva corresponderia a um valor em torno de $35 \%$. Com tal porosidade e uma espessura média de $10 \mathrm{~m}$ de areias arcoseanas, numa área de apenas 10x $106 \mathrm{~m} 2$ (por exemplo, $1000 \mathrm{~m}$ x $1000 \mathrm{~m}$ ), encontra-se armazenado e disponível nas camadas aqüíferas da Formação Guabirotuba um volume da ordem de $3.500 .000 \mathrm{~m} 3$ de água.

\subsubsection{COEFICIENTE DE PERMEABILIDADE}

$O$ valor do coeficiente de permeabilidade foi obtido através de ensaios de bombeamento e calculado com a fórmula de THEIS (1935; eq. 2).

A espessura das camadas aqüíferas (b) foi considerada como sendo igual a extensão dos filtros (hs) que foram instalados em cada poço. De acordo com os poços analisados, as espessuras do aqüífero na região e seus correspondentes coeficientes de permeabilidade, são apresentados na tabela 1.

Tabela 1 - Coeficiente de permeabilidade das camadas aqüíferas da Formação Guabirotuba.

\begin{tabular}{c|c|c}
\hline Poço & $\mathrm{b}=\mathrm{h}_{\mathrm{s}}(\mathrm{m})$ & $\mathrm{K}\left(\mathrm{m} \mathrm{x} \mathrm{s}^{-1}\right)$ \\
\hline № 7 & 12 & $1,22 \bullet 10^{-4}$ \\
\hline № 8 & 12 & $1,96 \bullet 10^{-4}$ \\
\hline № 3 & 16 & $1,32 \cdot 10^{-4}$ \\
\hline
\end{tabular}

\subsubsection{COEFICIENTE DE TRANSMISSIVIDADE}

O valor do coeficiente de transmissividade do aqüífero foi obtido através de ensaios de bombeamento e calculado com a fórmula de THEIS (1935; eq. 2), para uma condição de regime de bombeamento não-estabilizado. A referida fórmula é apresentada da seguinte forma:

$$
s=\frac{Q}{4 \cdot \pi \bullet T} \bullet W(u)=\frac{0,0795 \bullet Q}{T} \bullet W(u)_{\mathrm{B}}
$$

onde , $s=$ rebaixamento em metros, em qualquer ponto nas proximi-dade do poço bombeado com vazão constante; $Q=$ vazão do poço, em $\mathrm{m} 3 \times \mathrm{h}-1 ; T=$ coeficiente de transmissividade; $\mathrm{m} 2 \mathrm{x}$ h-1; $W(u)=$ "função $u$ do poço", provém da seguinte integral:

$W(u)=\int_{u}^{-\infty}\left(\mathrm{e}^{-\alpha}\right) /(u) \bullet d u=-0,5772-\log _{e} u+u-\frac{u^{2}}{2.2 !}+\frac{u^{3}}{3.3 !}+\frac{u^{4}}{4.4 !}+\cdots$ C
Nesta expressão,

$$
u=\frac{r^{2} \bullet S}{4 \cdot T \bullet t}
$$

onde, $r$ distância do centro do poço bombeado ao ponto onde é medido o rebaixamento em metros $(\mathrm{m}) ; S=$ coeficiente de armazenamento (adimensional); $T=$ coeficiente de transmissividade, $\mathrm{m}^{3} \mathrm{xh}^{-1}$ por metro de rebaixamento (ou $\mathrm{m}^{2} \times \mathrm{h}$ $\left.{ }^{1}\right) ; t=$ tempo a partir do início do bombeamento, em horas.

Os poços e os respectivos piezômetros com os quais foram desenvolvidos os ensaios de aqüífero, são apresentados na tabela 2 .

Tabela 2 - Poços e piezômetros utlizados no teste de aquífero.

\begin{tabular}{c|c|c|c|c}
\hline Poço & Piezômetro & $\begin{array}{c}\text { Vazão } \\
\left(\mathrm{m}^{3} \times \mathrm{h}^{-1}\right)\end{array}$ & Duração $(\mathrm{h})$ & $\begin{array}{c}\text { Distância } \\
(\mathrm{m})\end{array}$ \\
\hline $\mathrm{I}-07$ & $\mathrm{I}-05$ & 31,70 & 26 & 15 \\
\hline $\mathrm{I}-07$ & $\mathrm{I}-05$ & 18,40 & 4 & 15 \\
\hline $\mathrm{I}-03$ & $\mathrm{I}-05$ & 28,80 & 24 & 164 \\
\hline $\mathrm{I}-08$ & $\mathrm{I}-04$ & 19,80 & 20 & 350 \\
\hline $\mathrm{I}-08$ & $\mathrm{I}-09$ & 19,80 & 20 & 320 \\
\hline
\end{tabular}

Os valores de sobreposição dos rebaixamentos com a Curva de Theis, a partir dos quais foram calculados os coeficientes de transmissividade das camadas aqüíferas da Formação Guabirotuba, são apresentados na tabela 3.

Tabela 3 - Valores obtidos para o coeficiente de transmissividade, utilizando o método de Theis.

\begin{tabular}{c|c|c|c|c}
\hline$W(u)$ & $1 / u$ & $s(\mathrm{~m})$ & $t(\mathrm{~min})$ & $\begin{array}{c}T \\
\left(\mathrm{~m}^{2} \times \mathrm{h}^{-1}\right)\end{array}$ \\
\hline 4,25 & 200 & 2 & 100 & 5,30 \\
\hline 2,00 & 12 & 0,62 & 47 & 4,72 \\
\hline 0,80 & 29 & 0,24 & 26 & 7,63 \\
\hline 0,70 & 2,5 & 0,13 & 500 & 8,47 \\
\hline 1,00 & 3,7 & 0,43 & 280 & 3,66 \\
\hline
\end{tabular}

\subsubsection{COEFICIENTE DE ARMAZENAMENTO}

Os valores dos coeficientes de armazenamento do aqüífero foram obtidos através de ensaios de bombeamento e calculados com a fórmula de THEIS (eq. 2). Os resultados são apresentados na tabela 4.

O sentido geral de escoamento das águas das camadas aqüíferas da Formação Guabirotuba, é de sudeste para nordeste. Entre os poços I-9 e I-7 e entre I-9 e I-3, os valores dos gradientes hidráulicos são da ordem de 6 × 10-3 e $1 \times 10-2$, respectivamente. Este condicionamento pode ser visualizado na figura 2 , onde está bem detalhada a diferença de potencial do ponto "LEIT", cuja altura potenciométrica é igual a $879 \mathrm{~m}$, em relação ao ponto "AR3 ", onde a cota potenciométrica é igual a $875 \mathrm{~m}$. A direção de escoamento é ortogonal às linhas equipotenciais. 
Tabela 4 - Valores obtidos para o coeficiente de armazenamento, utilizando o método de Theis.

\begin{tabular}{c|c|c}
\hline Poço & Piezômetro & Coefic. de arnaz. \\
\hline № 7 & no 5 & $7,8 \cdot 10^{-4}$ \\
\hline № 7 & no 5 & $5,4 \cdot 10^{-3}$ \\
\hline № 3 & no 5 & $1,6 \bullet 10^{-5}$ \\
\hline № 3 & no 8 & $9,2 \cdot 10^{-4}$ \\
\hline № 8 & no 9 & $2,0 \cdot 10^{-4}$ \\
\hline \multicolumn{2}{|c}{}
\end{tabular}

3.3.5. VELOCIDADE DE ESCOAMENTO

A velocidade real $V_{R}$ varia de um ponto a outro no aqüífero. Em média, a velocidade real que a água escoa através dos interstícios de um aqüífero poroso é dada pela seguinte expressão:

$$
V_{R}=\frac{V_{a}}{n}
$$

onde $n$ é a porosidade do aqüífero expressa em fração decimal, $V_{R}$ representa, em média, a velocidade com que um indicador se deslocaria através de um meio poroso. No caso de aqüíferos constituídos de partículas muito finas, o $n$ é substituído pela porosidade efetiva $m_{e}$.

As velocidades do fluxo subterrâneo nas camadas aqüíferas da Formação Guabirotuba, na região delimitada pelos poços existentes, variam entre 6 x 10-3 e 3 x 10-6 m x $\mathrm{s}-1$. É interessante destacar que o fluxo ocorre da carga hidráulica mais elevada em direção a carga menos elevada, no sentido ortogonal as linhas equipotenciais.

\subsubsection{RECARGA DO AQÜÍFERO}

A variação da precipitação e da evaporação no decorrer do ano afeta diretamente a capacidade de infiltração e de recarga das camadas aqüíferas da Formação Guabirotuba, a partir do aqüífero livre. A recarga ocorre quando existe um excedente da precipitação em relação à evapotranspiração e ainda assim somente quando o solo encontra-se totalmente saturado segundo a sua capacidade máxima de retenção.

Considerando que a precipitação média anual é em torno de $1.400 \mathrm{~mm}$, que a evapotranspiração no mesmo período é igual a $679 \mathrm{~mm}$ e que o volume respectivo à capacidade de campo é igual a $150 \mathrm{~mm}$, a diferença entre o índice anual de chuvas em relação aos demais fatores é da ordem de $154 \mathrm{~mm}$ por ano. Este valor, o qual constitui um volume de 22.075.200 m3 por ano ou o equivalente a $5 \mathrm{Lx}$ $\mathrm{s}-1 \times \mathrm{km} 2$, representa o volume que o aqüífero livre cede sob a forma de recarga para as camadas aqüíferas da Formação Guabirotuba. A disponibilidade das águas subterrâneas, em termos de vazão, das camadas aqüíferas da Formação Guabirotuba, na área de abrangência da bacia hidrográfica do Iraí, gira em torno de 700 L x s-1.

A recarga das camadas aqüíferas foi calculada com o modelo matemático de UDLUFT (1988), a partir dos dados hidro-climatológicos respectivos ao período 1984 - 1993. Para a aplicação deste modelo, foi considerado $150 \mathrm{~mm}$ como valor para a capacidade de campo útil do solo e um grau de saturação do mesmo, respectivo ao mês de janeiro de 1984 , de $100 \%$. Os resultados são apresentados na tabela 5 .

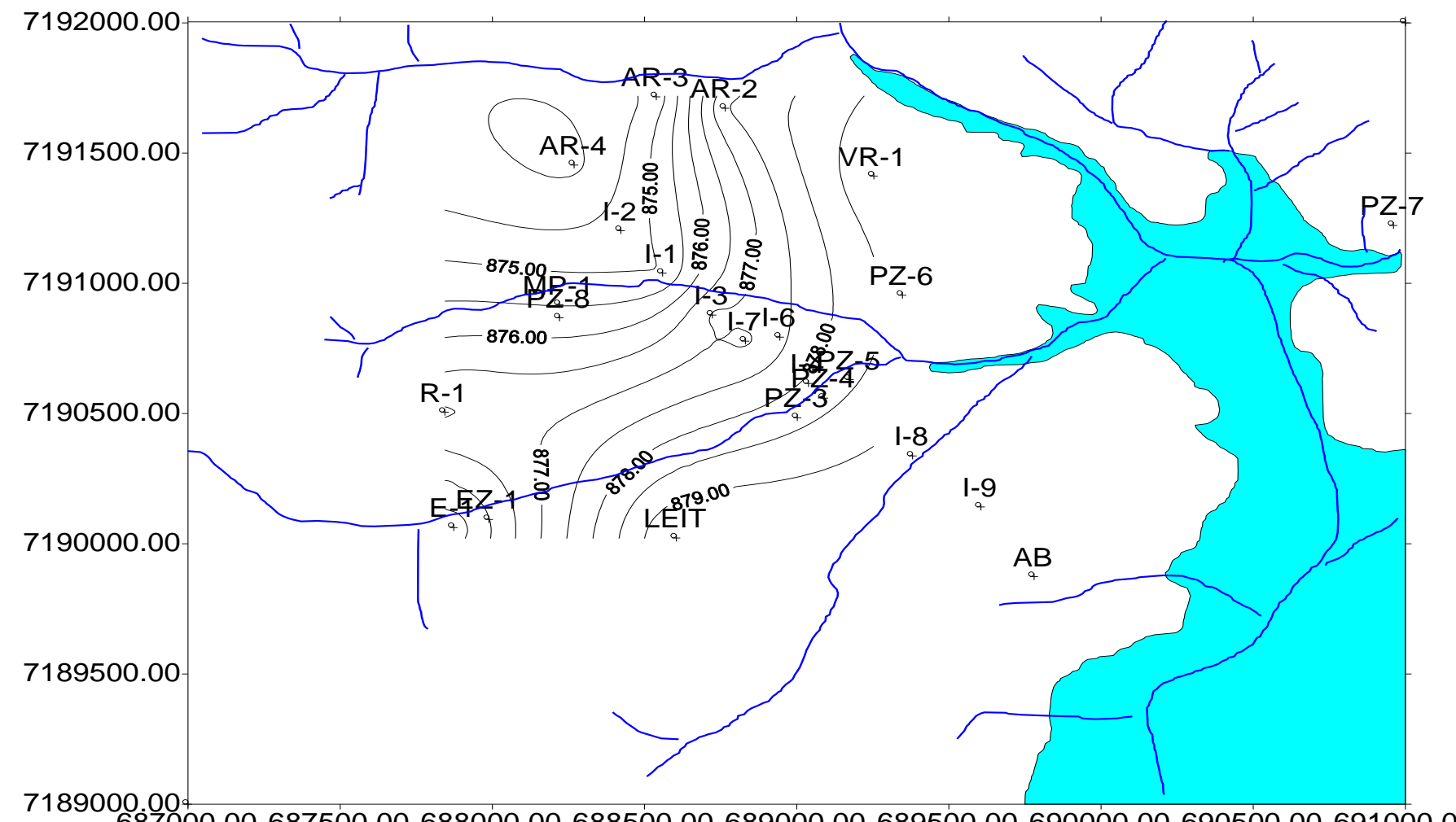

687000.00687500 .00688000 .00688500 .00689000 .00689500 .00690000 .00690500 .00691000 .00

Figura 2 - Linhas equipotenciais das camadas aqüíferas da Formação Guabirotuba (a cor azul clara representa a área alagada da barragem do Iraí). 
Tabela 5 - Distribuição da recarga (mm), período 1984-1993, calculada com o modelo MODBIL (UDLUFT, 1988).

\begin{tabular}{c|c|c|c|c|c|c|c|c|c|c|c}
\hline Ano & 84 & 85 & 86 & 87 & 88 & 89 & 90 & 91 & 92 & 93 & Med \\
\hline Jan & 59 & 21 & 11 & 32 & 61 & 13 & 205 & 50 & 14 & 17 & 86 \\
\hline Fev & 0 & 16 & 61 & 82 & 13 & 92 & 33 & 52 & 78 & 13 & 83 \\
\hline Mar & 93 & 44 & 54 & 0 & 82 & 53 & 117 & 13 & 10 & 69 & 75 \\
\hline Abr & 12 & 25 & 83 & 71 & 76 & 88 & 71 & 0 & 0 & 58 & 59 \\
\hline Mai & 39 & 0 & 36 & 20 & 21 & 66 & 30 & 0 & 13 & 12 & 85 \\
\hline Jun & 48 & 0 & 0 & 60 & 29 & 23 & 70 & 74 & 0 & 25 & 33 \\
\hline Jul & 0 & 0 & 0 & 0 & 0 & 74 & 175 & 0 & 63 & 30 & 34 \\
\hline Ago & 98 & 0 & 5 & 0 & 0 & 0 & 77 & 0 & 79 & 0 & 26 \\
\hline Set & 30 & 0 & 16 & 0 & 0 & 80 & 61 & 0 & 3 & 17 & 37 \\
\hline Out & 0 & 8 & 26 & 38 & 0 & 0 & 77 & 46 & 0 & 11 & 32 \\
\hline Nov & 11 & 0 & 14 & 0 & 0 & 0 & 140 & 0 & 10 & 0 & 50 \\
\hline Dez & 57 & 0 & 16 & 24 & 0 & 12 & 0 & 67 & 11 & 51 & 50 \\
\hline Soma & 65 & 26 & 70 & 51 & 59 & 73 & 1055 & 42 & 59 & 95 & 649 \\
\hline
\end{tabular}

Nos meses de junho a outubro, a infiltração é menos efetiva. Neste período, o somatório das alturas d'água que recarregam as camadas aqüíferas da Formação Guabirotuba corresponde a $162 \mathrm{~mm}$, enquanto a precipitação é de $453 \mathrm{~mm}$ e a evaporação real ou atual é igual a $274 \mathrm{~mm}$. O somatório médio dos índices mais elevados da recarga subterrânea, correspondente aos meses de janeiro a maio, atinge $388 \mathrm{~mm}$. A precipitação e a evaporação real, neste período, correspondem a $740 \mathrm{~mm}$ e $267 \mathrm{~mm}$, respectivamente.

A relação entre a recarga, a precipitação e a evaporação real pode ser visualizada na figura 3 .

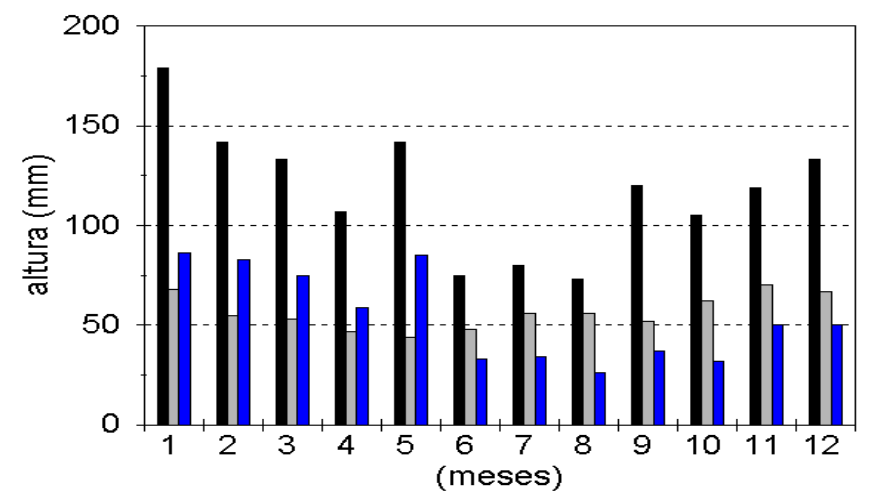

Figura 3 - Alturas médias anuais da precipitação, da evaporação real e da infiltração, respectivamente.

Com a finalidade de exemplificar a distribuição da recarga no decorrer do tempo, a partir dos cálculos obtidos com o modelo matemático MODBIL (UDLUFT, 1988), é apresentada a tabela 6 .

\subsection{Simulação matemática}

A maior dificuldade para simular a variação da potenciometria das camadas aqüíferas da Formação Guabirotuba, a partir do bombeamento de uma bateria de poços, deve-se a qualidade dos dados existentes. Esses dados referem-se as alturas do terreno para o estabelecimento das cotas potenciométricas, a correlação estratigráfica baseada nos perfis litológicos dos poços, a carência de dados sobre a qualidade das águas subterrâneas e a definição da extensão da estrutura geológica do tipo graben existente na área. Por estas razões, considera-se ainda necessária a perfuração de mais piezômetros na região, bem como a execução de caminhamentos elétricos para delimitar a extensão da estrutura geotectônica e a conformação da potenciometria hidráulica do aqüífero na região.

Os dados que permitiram a elaboração do mapa potenciométrico da região, foram extraídos da tabela 7.

Tabela 6 - Distribuição da recarga mensal em milímetros (exemplo do período 1984-1985) com início no mês de janeiro de 1984. CC = capacidade útil de campo $(150 \mathrm{~mm}) ; \mathrm{CSS}=$ condição de saturação inicial do solo (inicial $=100 \%) ; \quad P=$ precipitação; $E K=$ evaporação real; Rc = recarga.

\begin{tabular}{|c|c|c|c|c|c|}
\hline Mês & $\begin{array}{c}P \\
(\mathrm{~mm})\end{array}$ & $\begin{array}{c}\text { Ek } \\
(\mathrm{mm})\end{array}$ & $\begin{array}{l}P-E k \\
(m m)\end{array}$ & $\begin{array}{c}\text { CSS } \\
(\mathrm{mm})\end{array}$ & $\begin{array}{c}\mathrm{Rc} \\
(\mathrm{mm})\end{array}$ \\
\hline 1 & 149 & 85.0 & 58.8 & 150.0 & 58.8 \\
\hline 2 & 55 & 72.7 & -17.9 & 132.1 & 0.0 \\
\hline 3 & 174 & 54.7 & 110.6 & 150.0 & 92.7 \\
\hline 4 & 174 & 45.0 & 120.3 & 150.0 & 120.3 \\
\hline 5 & 91 & 51.0 & 39.0 & 150.0 & 39.0 \\
\hline 6 & 109 & 59.0 & 48.1 & 150.0 & 48.1 \\
\hline 7 & 47 & 64.0 & -17.1 & 132.0 & 0.0 \\
\hline 8 & 172 & 48.8 & 114.9 & 150.0 & 97.9 \\
\hline 9 & 110 & 78.0 & 30.1 & 150.0 & 30.1 \\
\hline 10 & 39 & 75.9 & -37.0 & 113.0 & 0.0 \\
\hline 11 & 218 & 50.0 & 149.8 & 150.0 & 112.8 \\
\hline 12 & 121 & 61.0 & 57.4 & 150.0 & 57.4 \\
\hline 13 & 86 & 64.0 & 21.2 & 150.0 & 21.2 \\
\hline 14 & 240 & 49.0 & 166.0 & 150.0 & 166.0 \\
\hline 15 & 95 & 50.0 & 43.8 & 150.0 & 43.8 \\
\hline 16 & 68 & 43.0 & 24.6 & 150.0 & 24.6 \\
\hline 17 & 14 & 57.2 & -43.2 & 106.8 & 0.0 \\
\hline 18 & 44 & 52.3 & -8.4 & 98.4 & 0.0 \\
\hline 19 & 20 & 46.0 & -26.0 & 72.4 & 0.0 \\
\hline 20 & 7 & 52.3 & -45.3 & 27.1 & 0.0 \\
\hline 21 & 139 & 36.0 & 98.9 & 126.0 & 0.0 \\
\hline 22 & 102 & 68.3 & 32.2 & 150.0 & 8.2 \\
\hline 23 & 49 & 84.6 & -35.7 & 114.3 & 0.0 \\
\hline 24 & 72 & 79.4 & -7.9 & 106.4 & 0.0 \\
\hline
\end{tabular}

A distribuição das cotas potenciométricas das camadas aqüíferas da Formação Guabirotuba na região de estudo, tal como mostrada na figura 2, foi calculada pelo método de Regressão Polinomial de Terceira Ordem (cubic surface). As linhas eqüipotencias mostram que o escoamento preferencial do fluxo subterrâneo é de sudeste (cota $879 \mathrm{~m}$ ) para noroeste (cota $875 \mathrm{~m}$ ). As principais zonas de recarga, neste caso, correspondem às áreas onde ocorrem os sedimentos recentes constituídos por aluviões, cujas espessuras máximas são da ordem de $4 \mathrm{~m}$, e que se 
Tabela 7 - Dados de cotas (potenciométrica, topo do migmatito, base dos sedimentos).

\begin{tabular}{|c|c|c|c|c|c|c|c|}
\hline Coord. & (ATM) & $\begin{array}{l}\text { Código } \\
\text { do poço }\end{array}$ & $\begin{array}{c}\text { Cota do } \\
\text { terreno (m) } \\
*\end{array}$ & $\begin{array}{c}\text { Nível } \\
\text { potenci. } \\
(\mathrm{m})^{*}\end{array}$ & $\begin{array}{c}\text { Topo } \\
\text { migmat. } \\
(\mathrm{m})^{*}\end{array}$ & $\begin{array}{l}\text { Base do } \\
\text { sediment } \\
(\mathrm{m})^{*}\end{array}$ & $\begin{array}{l}\text { Nível Hidrost. } \\
\qquad(\mathrm{m})\end{array}$ \\
\hline 689779,7 & 7189874 & $A B$ & & & & & 14,04 \\
\hline 688765,3 & 7191672 & AR-2 & 891,421 & 877,391 & 860,0 & 866,0 & 14,03 \\
\hline 688538,7 & 7191716 & AR-3 & 895,162 & 874,702 & 859,0 & 864,0 & 20,46 \\
\hline 688268,8 & 7191454 & AR-4 & 906,241 & 873,911 & 860,0 & 865,0 & 32,33 \\
\hline 687873,1 & 7190062 & $E-1$ & 901,833 & 875,153 & 866,0 & 871,0 & 26,68 \\
\hline 687988,8 & 7190093 & EZ-1 & & & & & \\
\hline 688559,6 & 7191039 & I-1 & 898,647 & 874,997 & 843,0 & 859,0 & 23,65 \\
\hline 688422,3 & 7191202 & $1-2$ & 909,932 & & 859,0 & 866,0 & \\
\hline 688722,9 & 7190878 & $1-3$ & 898,401 & 877,161 & 849,0 & 860,5 & 21,24 \\
\hline 689038,8 & 7190615 & I-4 & 893,445 & & 843,0 & 863,0 & \\
\hline 688044,8 & 7190793 & I-6 & 897,762 & & 853,0 & 863,9 & \\
\hline 688831,3 & 7190778 & $1-7$ & 898,635 & 876,845 & 853,0 & 863,0 & 21,79 \\
\hline 689380,9 & 7190337 & $1-8$ & 890,927 & & 840,0 & 862,8 & \\
\hline 689605,3 & 7190141 & $1-9$ & 894,330 & & 841,0 & 864,0 & \\
\hline 688604,6 & 7190022 & Leit. & 901,811 & 879,631 & & & 22,18 \\
\hline 688220,8 & 7190918 & MP-1 & 903,831 & & 850,0 & 858,9 & \\
\hline
\end{tabular}

encontra em contato com as camadas aqüíferas da Formação Guabirotuba (areias arcoseanas). O fluxo das águas subterrâneas em direção as áreas de descarga, supõe-se, alimenta as descontinuidades geoestruturais dos migmatitos, subjacentes. As águas do reservatório do Iraí, funcionaria como fonte de recarga artificial para as camadas aqüíferas da Formação Guabirotuba.

A modelação matemática foi realizada com o modelo "Processing MODFLOW", version 2.2. Os resultados mostram, numa primeira análise, as direções dos fluxos obtidos a partir das alturas potenciométricas medidas diretamente nos poços existentes, e as direções de escoamentos obtidas com os dados introduzidos no programa (espessuras e extensão das camadas saturadas, parâmetros hidráulicos, recarga do aqüífero, etc). Embora as diferenças nas formas das equipotenciais, o escoamento geral da água subterrânea é, em ambos os casos, de sudeste para noroeste, tal como pode ser visualizado na figura 4.

A direção do fluxo subterrâneo das águas que ocorrem nas camadas aqüíferas da Formação Guabirotuba, tal como mostrado na figura 3 e 4, é contrária à direção de fluxo das águas freáticas, as quais acompanham a morfologia do terreno, e das águas superficiais.

Para compensar a carência de dados e facilitar a simulação, foram introduzidos "dados auxiliares" nas partes que constituem os cantos do quadrado e em alguns pontos nos rios Iraí e Canguiri. Estes dados são apresentados na tabela 8.

Diante das dificuldades em adequar o modelo segundo as condições naturais do terreno, adotou-se as seguintes considerações:

a) A diferenciação da morfologia em termos de alturas do terreno, base e espessura das camadas aqüíferas; b) A inclinação hidráulica acentuada do aqüífero superior, fazendo com que as águas do reservatório hipodérmico (ou interflow) escoem rapidamente para os córregos da região;

c) A camada de sedimentos foi admitida como tendo 50 $\mathrm{m}$ de espessura e sendo constituída por uma mistura de areia-silte-argila. A modelação do nível potenciométrico foi feita através de uma relação direta entre a recarga do aqüífero e as áreas estabelecidas como de potencial fixo;

d) A segunda camada foi modelada como sendo constituída de uma mistura de areias e argilas, cuja espessura considerada foi de $10 \mathrm{~m}$. Na área próxima do rio Iraí, considerou-se uma redução desta camada de areiasargilas e na modelagem, nas mesmas áreas, foram feitas compensações através dos valores da permeabilidade vertical ( 8 x 10-8 $\mathrm{m}$ x s-1);

e) Como potencial fixo foi considerado para a primeira camada o nível da água dos rios Canguiri e Irai. A potenciometria inicial foi extraída da própria carta topográfica (escala 1:10.000) que por sua vez não apresenta dados muito confiáveis. $\mathrm{Na}$ primeira e na segunda camada, foi simulado o potencial fixo apenas para o rio Iraí.

f) A recarga nas camadas aqüíferas da Formação Guabirotuba foi admitida como sendo da ordem de $4 \mathrm{~L}$ x s-1 $x \mathrm{~km} 2$. As águas, a princípio, escoam para a região norte onde as distribuições das isolínhas (potenciometria) não se apresentaram de forma nítida. Nestas áreas foram necessárias acréscimos de "pontos de ajuda".

g) A descarga para norte foi simulada por meio da reservação de três camadas, sendo que no modelo foram admitidos vários poços organizados em fileiras com vazões variando de 0,00015 até 0,00005 L x s-1. Na área em questão, foi simulada a extração de $30 \mathrm{~L} \times \mathrm{s}-1$, o que corresponde a $70-80 \%$ da recarga. 


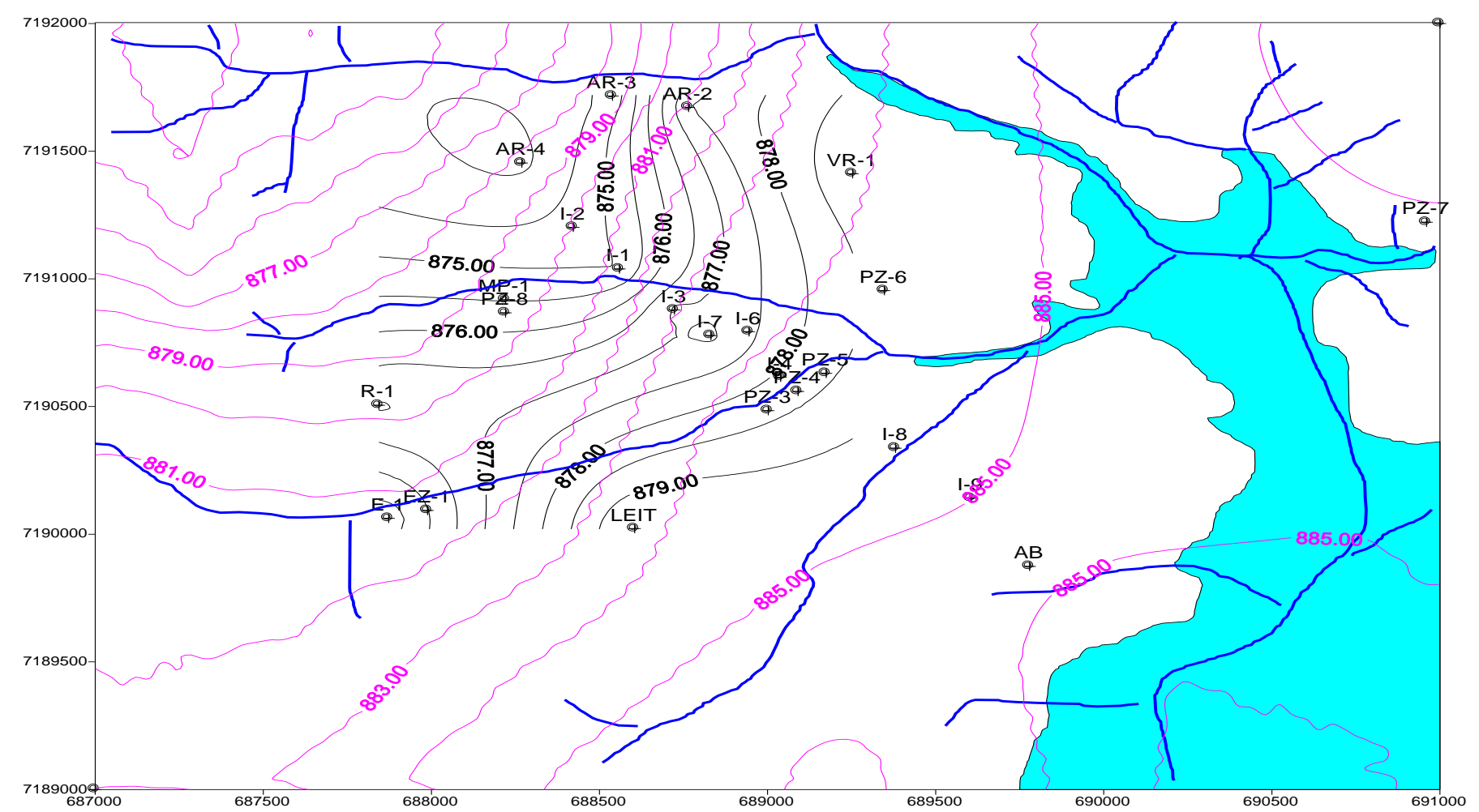

Figura 4 - Linhas equipotenciais das camadas aqüíferas da formação guabirotuba. obs: as linhas pretas foram traçadas com dados medidos nos poços; as linhas roxas representam o resultado da aplicação de dados mostrados na tabela 8.

Tabela 8 - "Dados auxiliares" utilizados na simulação.

\begin{tabular}{l|cllccccc}
\hline & $\begin{array}{c}\text { Espes } \\
(\mathrm{m})\end{array}$ & Aqǘf́fero & Poros. & $\begin{array}{c}\text { Perm. H } \\
\left(\mathrm{mxs}^{-1}\right)\end{array}$ & $\begin{array}{c}\text { Perm.V } \\
\left(\mathrm{mxs}^{-1}\right)\end{array}$ & $\begin{array}{c}\text { Potenc. } \\
\text { fixo }\end{array}$ & $\begin{array}{c}\text { Descar. } \\
\left(\mathrm{Lxs}^{-1}\right)\end{array}$ & $\begin{array}{c}\text { Recarg. } \\
\left(\mathrm{Lxs}^{-1} \times \mathrm{km}^{2}\right)\end{array}$ \\
\hline Camad.1 & 50 & Freático & 0,20 & $1 \bullet 10^{-4}$ & $1 \bullet 10^{-7}$ & Iraí, Can. & & 13 \\
Camad.2 & $5-10$ & Freático & 0,20 & $5 \bullet 10^{-9}$ & $5 \bullet 10^{-8}$ & Iraí & & \\
Camad.3 & $5-20$ & Semiconf & 0,28 & $5 \bullet 1-^{4}$ & $5 \bullet 10^{-5}$ & Iraí & 40 \\
\hline
\end{tabular}

O resultado da modelação básica, incluindo o balanço da água, é apresentado na figura 5 . O resultado mostra uma situação muito semelhante com a realidade. Percebese também um divisor de águas subterrâneas entre o poço $A B$ (Adalto Botelho) e o poço lapar 9 (I-9), e uma grande perda d'água proveniente da recarga na parte norte da área em que foi feita a simulação.

A modelação demonstrada na figura 6, simula a explotação da água armazenada nas camadas aqüíferas da Formação Guabirotuba, próxima dos poços I-8 e I-9, através de vinte poços tubulares, cada qual produzindo entre 5 e 10 $\mathrm{L}$ x s-1. O rebaixamento potenciométrico resultante é igual a $20 \mathrm{~m}$. Estes dados, todavia, não permitem afirmar se sob este regime de bombeamento o aqüífero permanecerá hidraulicamente confinado ou semiconfinado; os indícios são de que o rio Iraí funcionará como fonte de recarga do reservatório subterrâneo. Embora conste na figura 6 a existência do lago Iraí, a simulação matemática foi inicialmente realizada sem a carga imposta pelas águas do referido reservatório.

A modelação demonstrada na figura 7 simula a extração da água das camadas aqüíferas da Formação Guabirotuba com a existência do lago cuja altura da lâmina d'água corresponde a $888 \mathrm{~m}$ acima do nível do mar. A extração de
$150 \mathrm{~L}$ x s-1 resulta numa depressão de alguns metros sob condição de aqüífero confinado.

A construção das duas galerias de poços, cada uma com 10-15 poços ao longo do futuro lago do Iraí, está localizada entre 100-200 m de distância do mesmo. Esta é a melhor condição para a recarga artificial proveniente do lago artificial.

\section{Conclusão}

A direção de escoamento das águas armazenadas nas camadas aqüíferas da Formação Guabirotuba é contrária a da rede de drenagem e a do fluxo das águas freáticas. 0 lago Irai representa uma fonte de recarga das camadas aqüíferas do Guabirotuba, assim como a precipitação que, neste caso, é efetiva apenas onde as camadas mais grosseiras de materiais clásticos afloram na superfície do terreno.

A extração de $150 \mathrm{~L}$ x s-1 resultará num rebaixamento potenciométrico de $20 \mathrm{~m}$ ao entorno de uma bateria composta de 10 a 15 poços.

Embora a hidroquímica não seja objeto deste trabalho, é interessante destacar que a extração da água por meio de poços tubulares exigirá procedimentos para a retirada dos precipitados de ferro e manganês das secções filtrantes dos poços tubulares. 


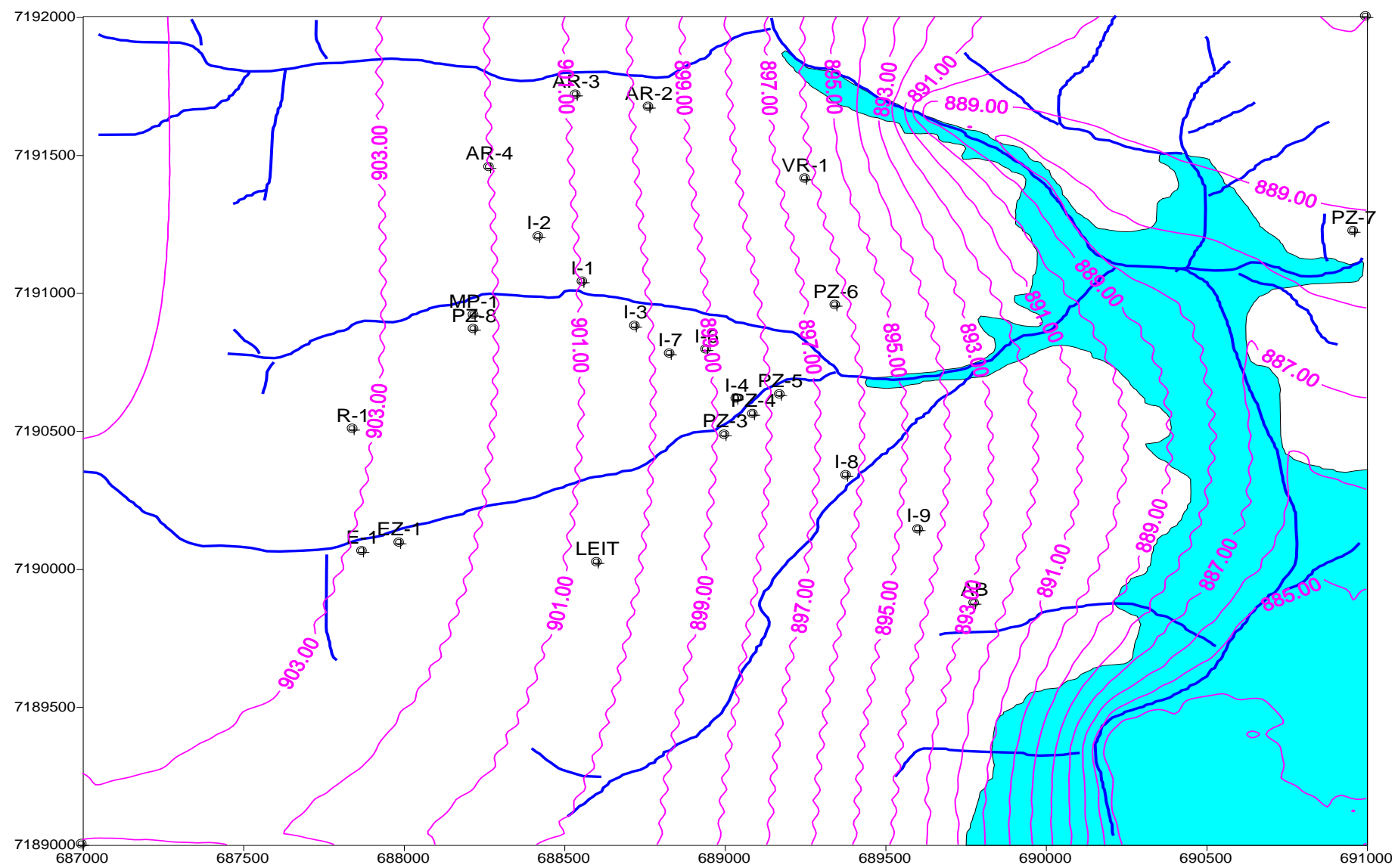

Figura 5 - Potenciometria do aqüífero freático obtido com a aplicação do modelo matemático (linhas em roxo = linhas equipotenciais).

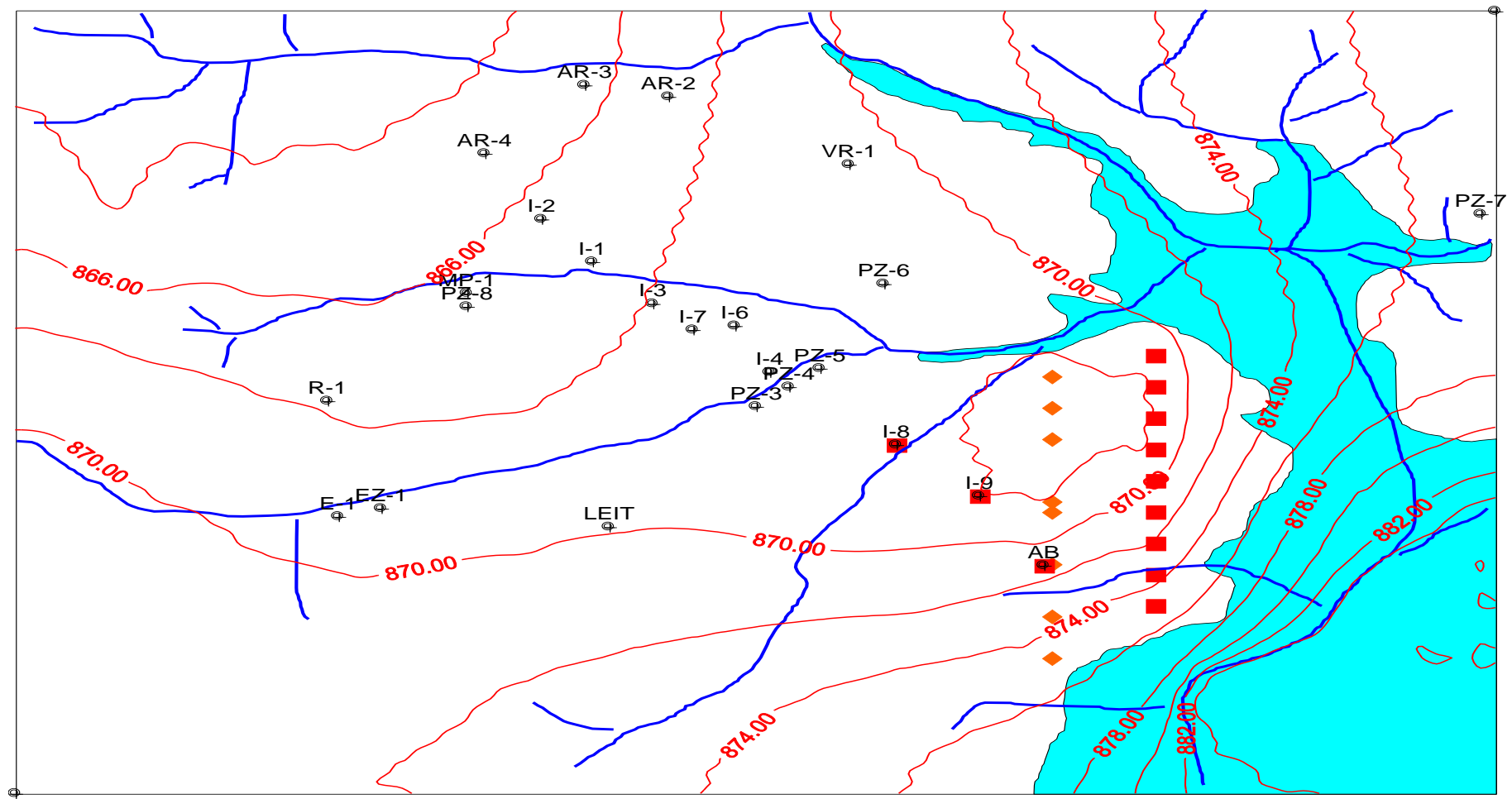

Figura 6 - Resultado da simulação com a implantação de vinte poços produzindo $150 \mathrm{~L}$ x s-1. 


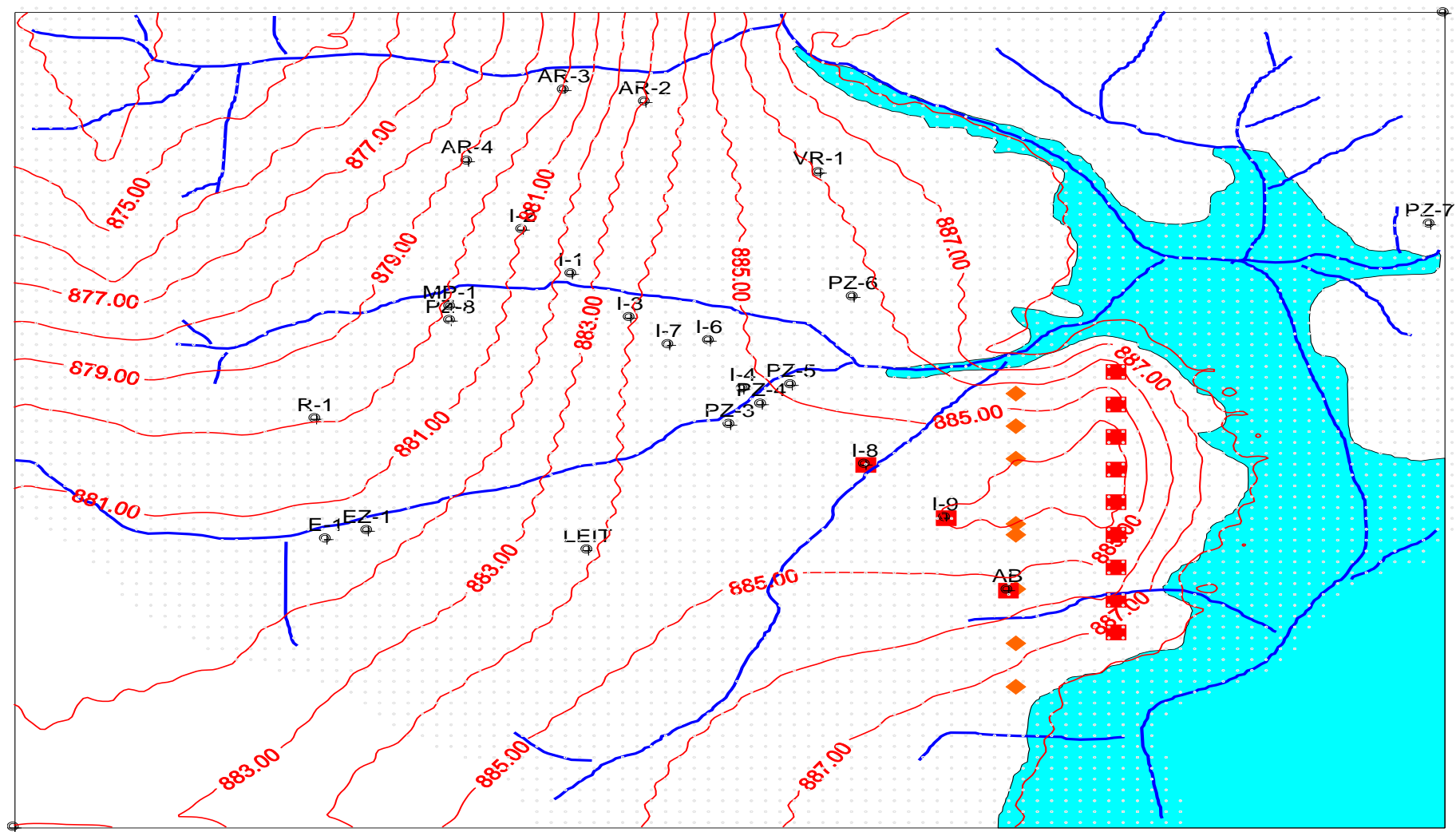

Figura 7 - Localização das duas galerias de poços com produção de $150 \mathrm{~L}$ x s-1 e linhas equipotenciais resultantes do bombeamento (nível da água do lago: $888 \mathrm{~m}$ ).

\section{Referências bibliográficas}

AB'SABER A.N., BIGARELLA J.J. 1961. Superfícies aplainadas no primeiro planalto do Paraná. Boletim Paranaense de Geografia. Curitiba, 13(4): 116-125.

ALMEIDA F.F.M. 1952. Novas ocorrências de camadas supostas pliocênicas nos Estados de São Paulo e Paraná. Boletim da Sociedade Brasileira de Geologia. São Paulo, 1(1): 53-58.

ARCHELA E. 1986. Faciologia e ambientes de sedimentação da Bacia de Curitiba, São Paulo, Instituto de Geociências da Universidade de São Paulo, Projeto de pesquisa

BECKER R.D. 1982. Distribuição dos sedimentos cenozóicos na região metropolitana de curitiba e sua relação com a estrutura geológica e morfológica regional, Porto Alegre, 1982. Tese de Doutorado. Universidade Federal do Rio Grande do Sul.

BERG E.A.T., LOURENÇO O.B. 1973. Sobre a composição mineralógica de argilas dos solos do Estado do Paraná. Boletim Paranaense de Geociências. Curitiba, 31: 13-30.

BIGARELLA J.J. 1971. Variações climáticas no Quaternário Superior do Brasil e sua datação radiométrica pelo método do Carbono 14. Paleoclimas. São Paulo. 1: 1-22.

BIGARELLA J.J., SALAMUNI R. 1958a Considerações sobre o paleoclima da Bacia de Curitiba. Boletim do Instituto de História Natural da Universidade Federal do Paraná. Curitiba, 1: 1-10,

BIGARELLA J.J., SALAMUNI R. 1952a. Notas complementares à planta geológica da cidade de Curitiba e arredores. Boletim do Instituto de Biologia e Pesquisas Tecnológicas. Curitiba, 40: 114.

BIGARELLA J.J., SALAMUNI R. 1962. Caractéres texturais dos sedimentos da Bacia de Curitiba. Boletim da Universidade Federal do Paraná. Curitiba, 7: 1-164.
BIGARELLA J.J., SALAMUNI R. 1962. Caracteres texturais dos sedimentos da Bacia de Curitiba. Boletim da UFPR - Geologia, 7: 1-159.

CARVALHO P.F. 1936. Geologia do Município de Curitiba. Boletim da Divisão de Geologia e Mineralogia. Rio de Janeiro, 82: 1-37.

COUTINHO J.M.V. 1955. Lantanita de Curitiba, PR. Boletim da Faculdade de Filosofia Ciências e Letras da Universidade Estadual de São Paulo. São Paulo, 13: 119-126.

FUCK R.A. 1966. Nota explicativa de folha geológica de QueroQuero. Boletim da Universidade Federal do Paraná. Curitiba, 19: $1-21$

FUCK R.A. 1967. Geologia da folha de Piraquara. 64p. (Datilografado).

GIRAO NERY G., ROSA FILHO E.Fda. 1994. Hidrogeofísica do poço da Fazenda Canguiri-PR. In: CONGRESSO BRASILEIRO DE ÁGUAS SUBTERRÂNEAS, 8.,Recife Anais...Recife, ABAS. Associação Brasileira de Águas Subterrâneas, .1: 363-371.

LEVORSEN A.I. 1954 Geology of Petroleum. Ed. San Francisco, W.h. Freeman and $\mathrm{Co}$.

LOPES J.A.V. 1966. Nota explicativa da folha geológica de Curitiba. Boletim da Universidade Federal do Paraná. Curitiba, 20: 1-20.

MAACK R. 1947. Breves notícias sobre a geologia dos Estados do Paraná e Santa Catarina. Arquivos de Biologia e Tecnlogia. Curitiba, 2: 142-158.

MARINI O.J. 1967. Geologia da folha de Araucária. Boletim da Universidade Federal do Paraná. Curitiba, 24: 1-22.

MURATORI A. 1966. Nota explicativa da folha de Campo Largo. Boletim da Universidade Federal do Paraná. Curitiba, 21: 1-31.

MURATORI A.M., GIUST D.A, CANALI N.E. 1982 Interpretação gravimétrica preliminar da configuração topográfica do 
Embasamento Cristalino no Município de Curitiba. In: CONGRESSO BRASILEIRO DE GEOLOGIA, 32., Salvador. Anais... Salvador, SBG. Sociedade Brasileira de Geologia, 4: 1576-1580.

OLIVEIRA A.I., LEONARDOS O.H. 1943. Geologia do Brasil. 2a ed, Rio de Janeiro, Ministério da Agricultura.

PETRI S., FÚLFARO V.J. 1983 Neocenozóico. In: GEOLOGIA DO BRASIL. São Paulo, EDUSP, 432-470

ROSA FILHO E.F.DA, PARANHOS FILHO A, PRAZERES FILHO H.DOS, VALESKI Z. 1996. Considerações sobre aspectos físicos e hidráulicos do aquífero Guabirotuba. Boletim Paranaense de Geociências. Curitiba, 44: 1-23.

SALAMUNI E. 1988. Tectônica da Bacia Sedimentar de Curitiba (PR). Tese de Doutorado. Rio Claro (SP).

SALAMUNI E., STELLFELD M.C. 2001. Banco de dados geológicos geo-referenciados da Bacia Sedimentar de Curitiba (PR) como base de sistema de informação geográfica (SIG). Boletim Paranaense de Geociências. 49:21-32

THEIS C.V. 1935 The relation between the lowering of the piezometric surface and the rate and duration of discharge of a well using ground water storage. Trans. Am. Geophysical Union. Washignton, 25: 519-524.

THORNTHWAITE C.W. 1948 An approach toward a rational classification of climate. Geologic. Rev., 38: 55-94

TREIN E.(Coord). 1969 Folha Geológica de Tijucas do Sul. Curitiba: Banco de desenvolvimento do Paraná S/A Comissão da Carta Geológica do Paraná Escala 1:70.000.

TURC L. 1954. Le bilan d'eau des sols; Relations entre les précipitations l'évaporation et l'écoulement. Ann. Agr. IV: 495-598. Paris.

UDLUFT P. 1988. MODBIL - Bilanzmenü zur Berechnung der Grundwasserneubildung mit verschiedenen Methoden. Vers. 3.1 - unverö. Computerprogramm. Universität Würzburg, Würzburg Deutschland. 